\title{
Mitochondrial DNA copy number in affected and unaffected LHON mutation carriers
}

\author{
Angelica Bianco ${ }^{1 \dagger}$, Alessio Valletti ${ }^{1 \dagger}$, Giovanna Longo ${ }^{1}$, Luigi Bisceglia², Julio Montoya ${ }^{3}$, Sonia Emperador ${ }^{3}$, \\ Silvana Guerriero ${ }^{1}$ and Vittoria Petruzzella ${ }^{1 *}$ (D)
}

\begin{abstract}
Objectives: Leber's hereditary optic neuropathy (LHON) is a mitochondrial genetic disease characterized by a variable and reduced penetrance. Individuals carrying a primary LHON-causing mitochondrial DNA (mtDNA) mutation may either remain asymptomatic lifelong, as unaffected carriers, or develop sudden central visual loss that rapidly aggravates over some weeks. Over the years several genetic/environmental triggers able to modulate the risk of developing LHON have been proposed. We provided data supporting a possible correlation between LHON penetrance and the mtDNA copy number, a raw index of mitochondrial mass, whose increase could represent a compensatory response that cells implement to alleviate the pathogenic effect of the primary LHON-causing mtDNA mutations.

Data description: We collected Italian and Spanish subjects harboring one of the three common LHON primary mutations, either in heteroplasmic or homoplasmic status. For each population we were able to discriminate between affected subjects presenting typical clinical tracts of LHON and LHON-causing mutation carriers showing no symptoms correlated with vision loss. Each subject has been characterized for the presence of a LHON primary mutation, for its status of homoplasmy or heteroplasmy, and for the mtDNA content per cell, expressed as relative mtDNA/ nDNA ratio respect to controls. Additional clinical information is present for all the Italian subjects.
\end{abstract}

Keywords: Incomplete penetrance, Leber's hereditary optic neuropathy, Mitochondrial genome, mtDNA copy number

\section{Objective}

Leber's hereditary optic neuropathy (LHON) is typically characterized by a rapid bilateral central vision loss owing to focal degeneration of the retinal ganglion cell layer and optic nerve $[1,2]$. The presence of primary mutations in mitochondrial DNA (mtDNA) is necessary, but not sufficient alone, to cause optic neuropathy, because disease penetrance can even vary within different families harboring the same mutation [3, 4]. Thus, the idea that other environmental and/or genetic factors might

\footnotetext{
*Correspondence: vittoria.petruzzella@uniba.it

${ }^{\dagger}$ Angelica Bianco and Alessio Valletti contributed equally to the work

1 Dipartimento di Scienze Mediche di Base, Neuroscienze e Organi di

Senso - Università degli Studi Aldo Moro, Piazza G. Cesare, 70124 Bari, Italy
}

Full list of author information is available at the end of the article affect the penetrance and the risk of developing LHON is being reinforced over the last years $[5,6]$. Nonetheless, when the etiology of a disease involves mitochondrial mutations it is mandatory to consider that the mtDNA is a multi-copy genome whose cell quantity varies depending on tissue type and pathophysiology factors. Furthermore, adjustment of the mtDNA content can represent a protective strategy cells perform to compensate whatever detrimental effect a mtDNA mutation is causing, whose efficacy is experimentally proven [7-9]. For instance, mitochondrial proliferation is commonly seen in postmitotic tissues such as skeletal muscle in patients with mitochondrial disease [10]. The mtDNA copy number can be assessed in peripheral blood and is thought to reflect variations in mitochondrial energetic function and 
biogenesis occurring in other tissues otherwise unaccessible for diagnostic tests [11].

The purpose of the data collected was to provide support to a possible correlation between the mtDNA levels and LHON penetrance in a population harboring a primary LHON-causing mutation. As already reported in other studies [12-16], unaffected mutation carriers showed the highest amount of mtDNA, regardless of the heteroplasmic/homoplasmic status. Furthermore, we observed that the mtDNA copy number progressively shifted towards higher values from controls to carriers, with the affected showing an intermediate value. This could suggest that in both carriers and affected individuals there is an activation of the mitochondrial biogenesis, somehow hindered in affected subjects.

\section{Data description}

We collected 124 subjects with a primary LHON-causing mutation (i.e., m.11778G $>$ A or m.3460G $>$ A), of which 51 Italians and 73 Spanish. Two different control groups were considered, specifically 90 unrelated Italian healthy subjects and 28 unrelated Spanish healthy subjects (Table 1-Data set 1-3) [17-19], the latter used only for the analysis of the homoplasmic Spanish population as this was analyzed in a different laboratory, even if following the same general procedures.

On the basis of clinical features and genetic mitochondrial analysis, we identified 46 Italians subjects, belonging to 20 families, carrying a LHON-causing mutation in homoplasmy $(37 \mathrm{~m} .11778 \mathrm{G}>\mathrm{A}$, distributed between 18 affected and 19 carriers, and 9 m.3460G $>$ A, of which 5 affected and 4 carriers) (Table 1-Data set 1) [17] and 52 Spanish (27 m.11778G $>$ A, distributed between 18 affected and 9 carriers, and 25 m.3460G $>$ A, of which 6 affected and 19 carriers) (Table 1-Data set 2) [18].

We also identified 26 subjects (Spanish and Italians), belonging to 12 families, carrying a LHON-causing mutation in heteroplasmy, distributed as follows (Table 1Data set 3) [19]: 9 subjects with the m.11778G $>$ A mutation (1 affected and 8 carriers), and 17 subjects with the m.3460G $>$ A mutation ( 4 affected and 13 carriers). The mutant allele frequency was variable, ranging from 30 to $95 \%$ and from 5 to $95 \%$ for $\mathrm{m} .11778 \mathrm{G}>\mathrm{A}$ and m.3460G > A, respectively.

These subjects were already partially described in our previous papers [13-15].

Subjects were collected at three sites: Ophthalmology Clinic, Policlinico Bari Hospital, Italy; Hospital IRCCS 'Casa Sollievo della Sofferenza', Italy; and the University of Zaragoza, Spain. Prior written and informed consent was obtained from each subject according to Institutional Guidelines. Several examinations were performed: slit-lamp biomicroscopy, fundal and optic nerve head stereoscopy, fluorescein angiography, optical coherence tomography, and visual field testing. Total genomic DNA was extracted using the "Wizard ${ }^{\circledR}$ Genomic DNA Purification Kit" (Promega) from peripheral blood of the patients and their relatives with suspicion of LHON and from healthy control subjects. The presence of LHON mutations (m.3460G $>\mathrm{A}, \mathrm{m} .11778 \mathrm{G}>\mathrm{A}$ and m.14484T $>$ C) was detected by PCR-RFLP and, if present, confirmed by direct sequencing (ABI prism 310, Applied Biosystems). Quantification of mtDNA copy number was performed by $\mathrm{qPCR}$ using the relative method [20]. Mitochondrial and nuclear DNA quantities were measured amplifying genomic regions of ND1 and B2M genes, respectively. $\mathrm{mtDNA} / \mathrm{nDNA}$ ratio was calculated for each sample and this value was then calibrated relative to the geometric mean of controls (i.e., relative mtDNA/nDNA ratio). For further details see Data file 1 (Table 1) [21].

Summing up the homoplasmic population data, in Italian subjects the mtDNA content (measured as relative mtDNA/nDNA ratio and expressed as geometric mean and confidence interval CI) was 100 (CI 93.38, 107.09) in controls, 133.72 (CI 112.34, 159.17) in affected and 173.97 (CI 140.53, 215.37) in carriers; in Spanish population we measured these mean values: controls 100 (CI 83.79, 119.35, affected 104.29 (CI 86.02, 126.44), and carriers 147.73 (CI 124.82, 174.84).

Table 1 Overview of data sets

\begin{tabular}{|c|c|c|c|}
\hline Label & Name of data file/data set & File types (file extension) & $\begin{array}{l}\text { Data repository and identifier (DOI or accession } \\
\text { number) }\end{array}$ \\
\hline Data set 1 & $\begin{array}{l}\text { Italian subjects with a LHON-causing mutation in } \\
\text { homoplasmy }[13,17]\end{array}$ & MS Excel file (.xIsx) & $\begin{array}{l}\text { Figshare (https://doi.org/10.6084/m9.figshare.70935 } \\
\text { 59.v1) }\end{array}$ \\
\hline Data set 2 & $\begin{array}{l}\text { Spanish subjects with a LHON-causing mutation in } \\
\text { homoplasmy }[15,18]\end{array}$ & MS Excel file (.xIsx) & $\begin{array}{l}\text { Figshare (https://doi.org/10.6084/m9.figshare.70936 } \\
\text { 19.v1) }\end{array}$ \\
\hline Data set 3 & $\begin{array}{l}\text { Italian and Spanish subjects with a LHON-causing } \\
\text { mutation in heteroplasmy }[14,19]\end{array}$ & MS Excel file (.xIsx) & $\begin{array}{l}\text { Figshare (https://doi.org/10.6084/m9.figshare.70936 } \\
\text { 43.v1) }\end{array}$ \\
\hline Data file 1 & Methods [21] & MS Word file (.docx) & $\begin{array}{l}\text { Figshare (https://doi.org/10.6084/m9.figshare.71338 } \\
\text { 40.v3) }\end{array}$ \\
\hline
\end{tabular}


Heteroplasmic subjects showed these relative mtDNA/nDNA ratio mean values: controls 100 (CI 93.38, 107.09), affected 140.25 (CI 89.51, 219.75) and carriers 234.54 (CI 197.45, 278.61).

\section{Limitations}

These data do not consider other known variables, such as mtDNA haplotypes and nuclear genetic background that represents likely triggers of LHON and are known to influence penetrance and age of onset.

\author{
Abbreviations \\ LHON: Leber's hereditary optic neuropathy; mtDNA: mitochondrial DNA; \\ nDNA: nuclear DNA; Cl: confidence interval.
}

\section{Authors' contributions}

VP conceived and designed the study, edited the main manuscript text and obtained funding. AB, GL, LB and SE conducted all the experiments and collected the data. $A B, V P$ and $A V$ analyzed the data and drafted the manuscript. LB, SG and JM provided the patient's samples, contributed in acquisition of data and in revising the manuscript critically. All authors read and approved the final manuscript.

\section{Author details \\ ${ }^{1}$ Dipartimento di Scienze Mediche di Base, Neuroscienze e Organi di Senso - Università degli Studi Aldo Moro, Piazza G. Cesare, 70124 Bari, Italy. ${ }^{2}$ Ospedale Casa Sollievo della Sofferenza IRCCS, UOC Genetica Medica, San Giovanni Rotondo, Italy. ${ }^{3}$ Departamento de Bioquímica y Biología Molecular y Celular, Universidad de Zaragoza-CIBER de Enfermedades Raras (CIBERER)-Instituto de Investigación Sanitaria de Aragón (IIS Aragón), 50013 Zaragoza, Spain.}

\section{Acknowledgements}

The authors thank the patients and their families for participating.

\section{Competing interests}

The authors declare that they have no competing interests.

\section{Availability of data and materials}

The data described in this Data note can be freely and openly accessed on Figshare data depository at https://doi.org/10.6084/m9.figshare.7093559.v1 (Data set 1) [17], https://doi.org/10.6084/m9.figshare.7093619.v1 (Data set 2) [18], https://doi.org/10.6084/m9.figshare.7093643.v1 (Data set 3) [19] and https://doi.org/10.6084/m9.figshare.7133840.v3 (Data file 1) [21]. Please see Table 1 for details and links to the data.

\section{Consent for publication}

Not applicable.

\section{Ethics approval and consent to participate}

Before recruitment into our study, all of the patients and the family members involved in the study, have signed written informed consent for the molecular studies and publication of the medical data of themselves. This consent was approved by the ethical committees of the Institutional Review Board 'Comitato Etico Interregionale', Azienda Consorziale Policlinico and University of Bari Aldo Moro. Research adhered to the tenets of the Declaration of Helsinki.

\section{Funding}

Funding by'Ricerca di Ateneo' 2011 and Petruzzella 00724113 Prin 2009 from the University of Bari, Bari, Italy was instrumental in providing support for design, collection and execution of the technical work and for analysis. An unconditional grant by Santhera Pharmaceuticals (Italy) was instrumental in writing the manuscript.

\section{Publisher's Note}

Springer Nature remains neutral with regard to jurisdictional claims in published maps and institutional affiliations.

Received: 28 September 2018 Accepted: 17 December 2018

Published online: 20 December 2018

\section{References}

1. Bi R, Zhang AM, Yu D, Chen D, Yao YG. Screening the three LHON primary mutations in the general Chinese population by using an optimized multiplex allele-specific PCR. Clin Chim Acta. 2010;411(21-22):1671-4.

2. Carelli V, Rugolo M, Sgarbi G, Ghelli A, Zanna C, Baracca A, et al. Bioenergetics shapes cellular death pathways in Leber's hereditary optic neuropathy: a model of mitochondrial neurodegeneration. Biochim Biophys Acta. 2004;1658(1-2):172-9.

3. Dimitriadis K, Leonhardt M, Yu-Wai-Man P, Kirkman MA, Korsten A, De Coo IF, et al. Leber's hereditary optic neuropathy with late disease onset: clinical and molecular characteristics of 20 patients. Orphanet J Rare Dis. 2014:9:158.

4. Howell N, Mackey DA. Low-penetrance branches in matrilineal pedigrees with Leber hereditary optic neuropathy. Am J Hum Genet. 1998;63(4):1220-4.

5. Carelli V, Ross-Cisneros FN, Sadun AA. Mitochondrial dysfunction as a cause of optic neuropathies. Prog Retin Eye Res. 2004;23(1):53-89.

6. Yu-Wai-Man P, Griffiths PG, Chinnery PF. Mitochondrial optic neuropathies-disease mechanisms and therapeutic strategies. Prog Retin Eye Res. 2011;30(2):81-114.

7. Bentlage HA, Attardi G. Relationship of genotype to phenotype in fibroblast-derived transmitochondrial cell lines carrying the 3243 mutation associated with the MELAS encephalomyopathy: shift towards mutant genotype and role of mtDNA copy number. Hum Mol Genet. 1996;5(2):197-205.

8. Toompuu M, Tiranti V, Zeviani M, Jacobs HT. Molecular phenotype of the np 7472 deafness-associated mitochondrial mutation in osteosarcoma cell cybrids. Hum Mol Genet. 1999;8(12):2275-83.

9. Wredenberg A, Wibom R, Wilhelmsson H, Graff C, Wiener HH, Burden SJ, et al. Increased mitochondrial mass in mitochondrial myopathy mice. Proc Natl Acad Sci USA. 2002;99(23):15066-71.

10. DiMauro S, Schon EA, Carelli V, Hirano M. The clinical maze of mitochondrial neurology. Nat Rev Neurol. 2013;9:429-44.

11. Clay Montier LL, Deng JJ, Bai Y. Number matters: control of mammalian mitochondrial DNA copy number. J Genet Genom. 2009;36(3):125-31.

12. Giordano C, Iommarini L, Giordano L, Maresca A, Pisano A, Valentino ML, et al. Efficient mitochondrial biogenesis drives incomplete penetrance in Leber's hereditary optic neuropathy. Brain. 2014;137(Pt 2):335-53.

13. Bianco A, Bisceglia L, Trerotoli P, Russo L, D'Agruma L, Guerriero S, et al. Leber's hereditary optic neuropathy (LHON) in an Apulian cohort of subjects. Acta Myol. 2017;36(3):163-77.

14. Bianco A, Bisceglia L, Russo L, Palese LL, D'Agruma L, Emperador S, et al. High mitochondrial DNA copy number is a protective factor from vision loss in heteroplasmic Leber's hereditary optic neuropathy (LHON). Invest Ophthalmol Vis Sci. 2017;58(4):2193-7.

15. Bianco A, Martinez-Romero I, Bisceglia L, D'Agruma L, Favia P, Ruiz-Pesini E, et al. Mitochondrial DNA copy number differentiates the Leber's hereditary optic neuropathy affected individuals from the unaffected mutation carriers. Brain. 2016;139(Pt 1):e1.

16. Bianco A, Bisceglia L, De Caro MF, Galeandro V, De Bonis P, Tullo A, et al. Leber's hereditary optic neuropathy, intellectual disability and epilepsy presenting with variable penetrance associated to the $\mathrm{m} .3460 \mathrm{G}>\mathrm{A}$ mutation and a heteroplasmic expansion of the microsatellite in MTRNR1 gene_case report. BMC Med Genet. 2018;19(1):129.

17. Bianco A, Valletti A, Longo G, Bisceglia L, Montoya J, Emperador S, et al. Data set 1: collection of clinical and molecular data of 46 Italian subjects with a LHON-causing mutation in homoplasmy and 90 control subjects. Figshare 2108. https://doi.org/10.6084/m9.figshare.7093559.v1.

18. Bianco A, Valletti A, Longo G, Bisceglia L, Montoya J, Emperador S, et al. Data set 2: collection of 52 Spanish subjects with a LHON-causing 
mutation in homoplasmy and 28 control subjects. Figshare 2018. https:// doi.org/10.6084/m9.figshare.7093619.v1.

19. Bianco A, Valletti A, Longo G, Bisceglia L, Montoya J, Emperador S, et al. Data set 3: collection of 5 Italian and 21 Spanish subjects with a LHONcausing mutation in heteroplasmy and 90 control subjects. Figshare 2018. https://doi.org/10.6084/m9.figshare.7093643.v1.
20. Pfaff MW. A new mathematical model for relative quantification in realtime RT-PCR. Nucleic Acids Res. 2001;29(9):e45.

21. Bianco A, Valletti A, Longo G, Bisceglia L, Montoya J, Emperador S, et al. Data file 1: detailed methodology for BMC research notes paper by Bianco A et al. Figshare 2018. https://doi.org/10.6084/m9.figshare.71338 40.v3.
Ready to submit your research? Choose BMC and benefit from:

- fast, convenient online submission

- thorough peer review by experienced researchers in your field

- rapid publication on acceptance

- support for research data, including large and complex data types

- gold Open Access which fosters wider collaboration and increased citations

- maximum visibility for your research: over 100M website views per year

At BMC, research is always in progress.

Learn more biomedcentral.com/submissions 